\title{
ARTE, LOUCURA E CIDADE: A INVENÇÃO DE NOVOS POSSÍVEIS
} ART, MADNESS AND CITY: THE INVENTION OF NEW POSSIBLE

\author{
Mariana Tavares Cavalcanti Liberato e Magda Dimenstein
}

Universidade Federal do Rio Grande do Norte, Natal, Brasil

\begin{abstract}
RESUMO
O presente trabalho intenta discutir as possibilidades trazidas pela arte no contexto da desinstitucionalização da loucura. Propõe-se que tal dispositivo pode ir além de um uso meramente instrumental e disciplinador, criando novos regimes de visibilidade e de sociabilidade no cotidiano urbano. Nesse sentido, apresentamos algumas imagens que nos ajudam a refletir sobre a potência da arte e debatemos algumas ações que estão em curso a partir do "Projeto Arte e Saúde". A despeito das dificuldades vivenciadas, observamos que a produção de encontros derivados dessas experiências aponta para outras formas de lidar com a diferença e vivenciar a cidade por meio da arte.
\end{abstract}

Palavras-chave: arte; loucura; cidade; saúde mental; sociabilidade.

\begin{abstract}
This paper aims to discuss the possibilities brought by art in the context of deinstitutionalization of madness. It is proposed that such device can go beyond a merely instrumental and disciplinary use, creating new systems of visibility and sociability in daily urban life. In this sense, we present some images that help us to reflect about the strength of art and we discuss about some actions that are underway in the city originated from "Projeto Arte e Saúde". Despite the difficulties experienced, we observed that the productions of meetings derived from these experiments points to other ways of dealing with difference and experience the city through the art.
\end{abstract}

Keywords: art; madness; city; mental health; sociability.

As relações entre arte e loucura desenvolveramse e ganharam uma maior especificidade a partir do século XIX, com o uso da arte como ferramenta em atividades dentro dos hospitais psiquiátricos e com a consequente criação de diferentes teorias a respeito dessas. Na Europa, até antes do século XVIII, uma das recomendações para lidar com a loucura, ainda não concebida como doença mental, era assistir às encenações teatrais, que serviriam como um espaço propício para o reconhecimento do engano e da ilusão, mediante o contato com um universo fictício (Foucault, 2003). Logo, não foi apenas a partir da concepção da loucura como doença mental e da arte como instrumento de tratamento no hospital que nasce a relação entre esses dois campos, mas foi a partir desse momento que tal debate ganhou novos olhares e sentidos.

Tomando essa afirmação como ponto de partida, o presente trabalho busca refletir acerca de como esta articulação entre arte-loucura pode ir além e transbordar um uso objetivo e instrumental da primeira, que, em muitos momentos, finda por buscar controlar e apaziguar a segunda. A arte, desse modo, seria vista apenas como uma ferramenta de entretenimento ou uma mera ocupação, não sendo valorizada como um possível vetor de transformação e ressignificação das relações e da própria vida.

Parte-se, pois, do pressuposto de que a experiência sensível propiciada pela arte manifestase como um acontecimento ${ }^{1}$, como potência de desestabilização das formas já postas. Seu poder de afecção extravasa o produto final, colocando em devir os fluxos que atravessam tanto o artista (entendido aqui de modo mais abrangente que a figura do artista acadêmico), como quem a contempla efetivamente (Deleuze \& Guattari, 1992).

As reflexões que se seguem pretendem apontar em direção a esta forma distinta de lidar com a arte, como vetor de subjetivação, dispositivo desinstitucionalizante e estratégia de resistência, buscando a criação de agenciamentos que desconstruam estigmas e possibilitem a invenção de territórios existenciais singulares e de outros caminhos em direção à alteridade. A partir dessas ideias, desejamos 
discutir também sobre algumas articulações entre arte e saúde mental que estão em curso no processo de consolidação do paradigma de atenção psicossocial e da Reforma Psiquiátrica na cidade de Fortaleza/ CE. Acrescentamos a esta relação, assim, um terceiro elemento, que se apresenta como imprescindível para pensarmos tais questões: sua relação com a cidade.

a rua é condição necessária à arte e à loucura. Nas experiências antimanicomiais, a rua é companheira e não somente lugar a ser alcançado. ... A cidade, a arte e a loucura, em parceria, apelam por outra sensibilidade, mais plural e menos normativa. (Martins, 2009, p. 87)

Tomamos como premissa básica debater sobre os espaços construídos no território urbano que possibilitam o contato com a diferença, apresentando a arte como estratégia de potencialização de novos modos de existência e de lutas coletivas, bem como questionamo-nos acerca dos embates e encontros que os espaços da cidade, através da articulação de diferentes redes, podem possibilitar na construção de outros modos de relação com a diferença. Ao buscarmos operar a partir da lógica da desinstitucionalização da loucura, perguntamo-nos se não seria preciso também criar estratégias no que tange à desinstitucionalização do próprio espaço da cidade e das relações que nela são tecidas. Não seria este o cerne da proposta de desconstrução do lugar da loucura: a criação de diferentes formas de (con)viver com a diferença e habitar a urbe?

Nesse intuito, iniciaremos apresentando algumas inquietações, livremente inspiradas em três imagens relativas a percepções sobre cidade, que estiveram presentes desde as primeiras reflexões que constituíram este trabalho e que nos levam a pensar sobre os múltiplos encontros, atuais e virtuais, possíveis entre arte-loucura-cidade.

\section{O postulado da "Cidade Ideal" e seus regimes de visibilidade na sua relação com a Arte e a Loucura}

Uma imagem que tem nos acompanhado e que sempre retorna quando refletimos sobre esse tema é a da cidade ideal, preconizada por Platão no seu diálogo "A República". Nela, todos os cidadãos (reconhecidos como tal) têm uma função definida (políticos, artesãos, soldados) e participam, com o seu trabalho, na manutenção dessa estrutura. Contudo, há algo que transborda a ordem das necessidades racionais. Há um excesso perigoso que ameaça toda essa lógica, provocando o erro e a ilusão: a arte.
Para Platão, o artista é um fabricante de imagens fantasmas que desviam os olhos do cidadão das verdadeiras ideias, que só podem ser apreensíveis pelo pensamento. Além disso, a arte estimula as paixões, os afetos e as emoções, tais como a alegria, a tristeza ou a raiva, que deixadas sem controle podem conduzir em última instância à guerra e à catástrofe. A arte só deveria ser praticada por crianças, mulheres, escravos ou loucos, enfim, somente aqueles que não têm nada a perder. (Feitosa, 2004, p. 116)

Há nesta imagem de cidade a busca por uma organização racional e metódica do governo entre iguais. Todavia, as paixões trazidas pela arte podem embaçar tal racionalidade, comprometendo o bemestar dos seus cidadãos. Desse modo, os artistas não são bem-vindos na cidade ideal, visto trazerem o engodo, a ilusão e o descontrole. Apenas "aqueles que não têm nada a perder", os não-cidadãos, aqueles que, de fato, já não participam da polis, podem praticar a arte. Guardemos, por um instante, tal imagem.

Outras duas imagens que sempre se fazem presente em nossas reflexões derivam de algumas memórias intensivas de uma das autoras de sua própria vivência na cidade de Fortaleza. A primeira refere-se a um incômodo antigo, mas que levou algum tempo para ser significada, exatamente pela falta de enunciação das questões que a sustentam. Expliquemos melhor.

O curso de graduação que frequentamos há algum tempo atrás se localiza em um bairro muito tradicional da cidade, conhecido por ser ponto de encontro para pensadores, artistas, boêmios, pessoas que sempre viveram e trabalharam por lá, alunos e professores, além de manter espaços, que acolhem diferentes manifestações artístico-culturais em seu entorno. Podemos dizer, com isso, que tal lugar sempre nos pareceu muito vivo, com uma efervescência bem típica.

Aos nossos olhos de estudantes àquela época, tal lugar propiciava a convivência (nem sempre pacífica, obviamente) de diferentes atores sociais que por ali não só transitavam, como também se demoravam, criando diferentes relações de pertencimento e de sociabilidade. Contudo, havia algo, ali, que escapava a toda essa agitação. Pior, escapava, até mesmo, dos olhos dos que sempre passavam e se encantavam com essa ocupação dos espaços públicos.

$\mathrm{Na}$ mesma avenida na qual fica a faculdade, um pouco antes, o barulho daquele bairro tão habitado ia se perdendo e não era por conta do museu da Universidade ou da igrejinha antiga que lá estava. Mesmo nesses lugares em que, normalmente, se exige silêncio, havia uma relação com o fora, um fluxo de entrada e saída. Naquele prédio adiante, não. Havia 
um silêncio diferente e mais entradas que saídas. Fluxos interrompidos, relações também. Naquele prédio, ainda hoje, funciona um dos hospitais psiquiátricos privados (mas também conveniado ao SUS) da cidade.

Antes de entrar na faculdade, sempre passamos em frente a tal hospital, sem nunca darmos muita atenção para ele. Em nossa imaginação, era apenas mais um local de tratamento, como qualquer outra unidade hospitalar que já conhecíamos. Já na Universidade, tivemos a oportunidade de ir conhecer tal lugar, como atividade para uma disciplina. Descobrimos, então, que não era um hospital igual àqueles que procuramos quando estamos com uma virose ou uma fratura. Descobrimos, principalmente, a impossibilidade de ir e vir e o silêncio subjetivo e atordoante que essa impossibilidade trazia.

Não nos foi possível entrar no hospital para conhecê-lo, conforme a atividade da disciplina (só pudemos entrar na sala da direção do hospital). Todas as outras equipes da turma, que foram visitar outros hospitais psiquiátricos diferentes, tiveram algum acesso em suas visitas. Procuramos a professora responsável pela disciplina para discutir a situação e a resposta que obtivemos foi a de procurar outra instituição. Não lembro, de fato, de termos debatido sobre as questões essenciais que se colocavam a partir daquela impossibilidade. Naquela época, se a discussão sobre a Reforma Psiquiátrica ainda passava ao largo daquela avenida do curso de Psicologia, que diríamos do resto da cidade?

Asegundaimagem, quenos provoca o pensamento no que tange a um regime de visibilidade homogêneo, se delineou através de uma experimentação artística realizada por uma das autoras junto a um coletivo de artistas-pesquisadores em um prédio semiabandonado na orla de Fortaleza ${ }^{2}$.

Possuidor de uma arquitetura singular, que lembra um navio, o Edifício São Pedro divide-se em duas partes: uma residencial, ainda habitada, e outra que, em tempos passados, foi um hotel de nome Iracema Plaza, que se encontra desativado. Tal hotel foi o primeiro a se estabelecer na orla marítima da Praia de Iracema, em Fortaleza, que ficou conhecida, posteriormente, como rota de turismo da cidade.

Embora sua fachada esteja deteriorada, com pintura desgastada, vidraças quebradas e seu entorno tenha sido esvaziado com o declínio de tal área como reduto boêmio e turístico, a edificação mantém sua beleza e imponência, situando um de seus lados numa via movimentada da cidade. A despeito disso, ela se mostrava invisível para tantos que sempre passavam por ali e que só a (re)descobriram a partir do olhar estético da intervenção, que a produziu sob um outro regime de visibilidade, o da arte.

Tal "invisibilidade" nos instigou a pensar sobre o modo como habitamos a cidade, no entrecruzamento de tantos fluxos e velocidades que muitas vezes esvaziam de sentido lugares, coisas e pessoas. Além disso, notamos também que tal forma de subjetivação está intrinsecamente ligada a uma lógica da utilidade, que produz um tempo que é o da pressa e um espaço que é o do privado. As relações, assim, se modificam e constituem configurações subjetivas que, em muitos casos, nos enclausuram e nos apartam do contato com o diferente. Produção de uma cidade asséptica, cômoda, confortável, na qual nada interfira na nossa passividade e nos desestabilize. Habitar artisticamente o São Pedro nos possibilitou entrar em contato com questões essenciais, tais como a relação de cada um com a cidade e com o espaço dos restos; a possibilidade de resistir através da arte e a necessidade de refletirmos sobre como tudo isso atravessa e constitui nossos corpos, nossas subjetividades.

É importante destacar que ao falarmos de resistência não nos referimos apenas a uma forma de sobrevivência ou tão somente a uma ação reativa. A noção de resistência que desejamos evocar diz respeito a uma "vontade ativa de resistir", de compor novas linhas de fuga, de ser afetado pelas forças do fora (Oneto, 2006), pela intensidade dos afetos que nos movem à invenção de outros possíveis.

Trazemos essas memórias, então, para refletirmos a respeito dos movimentos de visibilidade e invisibilidade, do que pode e deve ser visto e enunciado em contraposição àquilo que deve ser escondido, negado, por aparecer como diferença radical, como algo que destoa. Assim como a loucura. A arte teria, então, potência de produzir novos regimes de visibilidade e enunciação para a loucura e para a cidade? Procuremos refinar um pouco mais nossas reflexões.

Todas essas imagens servem não apenas como ilustração ao nosso debate, mas, principalmente, como disparadoras de nossas questões atuais. Pensar a arte no contexto da Reforma Psiquiátrica é refletir acerca de sua potencialidade como dispositivo de transformação; mas é, ao mesmo tempo, indagar sobre os perigos de sua utilização como ferramenta de reprodução e sobrecodificação da existência.

Nos exemplos citados, vimos que as relações estabelecidas entre arte e cidade são bastante complexas. Enquanto no ideal de urbe platônico os artistas deveriam ser expulsos para que não 
propiciassem o engano e a desmesura da paixão, em um exemplo da contemporaneidade vimos a arte definir novas visibilidades. Em relação ao outro exemplo, podemos, apenas, conjecturar se a arte, naquele contexto, poderia criar outras porosidades para além do que está estabelecido como convivência possível.

De toda forma, observamos que a arte da qual estamos tratando define-se não como representação ou reprodução de algo já dado, mas aponta para invenção de novas formas de ver e de se relacionar. Desse modo é que nos inquietou pensar como a arte poderia vincular outros espaços para a loucura na cidade. $O$ que se encontra invisível e indizível na relação loucura-cidade? Que modos de vida a cidade constrói em seu cotidiano de velocidade e de consumo? Que resistências são engendradas aí?

\begin{abstract}
A cidade aparece nas experiências antimanicomiais menos como um lugar a ser habitado, mas ela própria como uma experiência. Não há uma cidade dada de antemão, assim como não há um sujeito originário. Reivindica-se a cidade, pois é nela que as disputas de força deixam de ser vivências individuais e confessionais para imprimirem-se com toda força no coletivo. Logo, o território está longe de ser um lugar confortável, nele todos são vulneráveis e tudo é imprevisível. (Martins, 2009, p. 82)
\end{abstract}

Nesse sentido, podemos nos aproximar do conceito de território e entendê-lo não como algo já dado e livre de conflitos. Ao contrário. É importante ressaltarmos que ao falarmos em território não estamos nos referindo somente a uma região ou distrito administrativo, mas ao lugar onde são tecidas as relações sociais. Como já foi enunciado por Milton Santos: "É o uso do território, e não o território em si mesmo, que faz dele objeto da análise social" (Santos, 2005 , p. 7). Aproximando tal compreensão da ótica da Saúde Mental Coletiva em relação a esse conceito, podemos compreender que ele se constitui a partir dos espaços de encontro e de enfrentamento pautados nas relações sociais, políticas, afetivas e ideológicas de determinado lugar (Lancetti \& Amarante, 2009). Exatamente por ir além de uma definição meramente espacial, devemos estar atentos a toda tensão e contradição existentes em determinado lugar.

Logo, todos esses arranjos, agenciamentos e choques devem ser tomados como parte efetiva da construção de novos territórios materiais e subjetivos. O processo de Reforma, então, apresenta-se como lutas e conquistas não de uma posição previamente delimitada para a loucura (seja ela a da doença, da tutela ou da compaixão), mas como campo de diferentes práticas de convivência e sociabilidade, que superem a normalização e o desejo hegemônicos de adaptação/adequação daquilo que aparece como destoante, desatino, ruína ou ruído.

Isso posto, constatamos que, além da criação de novos serviços substitutivos ao hospital psiquiátrico, é necessário libertarmo-nos de nossos manicômios mentais (Pelbart, 1993), que insistem em produzir o discurso da segregação, da opressão, da submissão. Assim, percebemos também que tais desejos de clausura e de distanciamento criam novos regimes de dentro e fora. Não basta derrubar paredes e muros de tijolos e cimento. Embora essa seja uma ação imprescindível e necessária, é urgente fomentar estratégias para a produção de novas sensibilidades, marcadas por uma maior abertura e por um menor temor, indiferença e desconfiança.

Reafirmamos, desse modo, que a experiência da desinstitucionalização não está na ordem apenas dos estabelecimentos de saúde e de suas mudanças técnicas, mas trata, fundamentalmente, de percebermos como somos todos atravessados por diversas normas sociais, nem sempre explicitamente enunciadas, que regulam de determinadas maneiras nossos modos de vida. Podemos, pois, perceber que a « instituição psiquiatria » encontra-se em nós também, assim como as instituições trabalho, família, dinheiro... Dessa forma, verificamos que a produção das formas de se relacionar no e com o espaço urbano estão atravessadas por essas (e por outras) instituições, o que nos faz reproduzir, muitas vezes, padrões, comportamentos e práticas sem se quer nos darmos conta.

Tomemos, como exemplo, a questão dos regimes de visibilidade comentados. Quantas vezes simplesmente tornamos invisível aquilo que não queremos ver, seja através de discursos ou práticas? Numa "cidade cartão-postal", apegada ao consumo de suas imagens turísticas, e em vidas tão padronizadas pela lógica capitalista da competitividade e do individualismo, quantas vezes buscamos esconder os que teimam em se diferenciar da paisagem, removendoos e confinando-os em algum lugar? Que fluxos são esses que esvaziam a existência, tornando-a lixo, refugo, resto? Que se preocupam mais com a imagem da propaganda do que com a potencialização da vida?

Contudo, "a fachada do prédio e o trânsito que o circula esconde pequenos ruídos de pés descalços que ainda correm procurando alívio" (Oliveira, 2004, s.p.). Pés que correm não para fugir ou escapar de algo, mas em busca de outros possíveis, de outras estratégias de enfrentamento, de luta, outros modos de resistir.

A partir desse pensamento, podemos voltar, então, a pensar nas possibilidades evocadas pela arte no contexto de nossa discussão, nas quais a 
experiência artística é compreendida como produtora de singularidades e novas sociabilidades, colocandose a serviço não do paradigma racional e cientificista, mas da experimentação de novas sensações através dos fluxos estéticos, em um paradigma também ético e político. Concordamos, pois, com Rancière (2005) na perspectiva de que a arte é política por modificar a paisagem da vida coletiva, configurando maneiras de estar junto ou separado, dentro ou fora.

\section{A produção de encontros entre Arte e Saúde Mental}

No âmbito macropolítico ${ }^{3}$ da Reforma Psiquiátrica, temos como uma das principais propostas de articulação do trinômio arte-loucura-cidade a criação dos Centros de Convivência e Cultura. De acordo com a Política Nacional de Saúde Mental (Ministério da Saúde, 2005), os Centros surgem como possibilidades de encontro, circulação e reapropriação do espaço público não só pelos usuários da rede de saúde mental com transtornos severos e persistentes e seus familiares, mas por toda comunidade. O trabalho desenvolvido nesses lugares, sob a forma de oficinas e atividades coletivas, conecta-se aos outros equipamentos do campo da saúde e também aos dispositivos da rede de assistência social, cooperativas e associações e propicia o combate ao estigma e à exclusão, promovendo a construção de novos laços sociais.

Constatamos durante nossa pesquisa que ainda não fora criado nenhum equipamento desse tipo vinculado à rede assistencial de saúde mental. Isso não significa, porém, que outras ações e articulações nesse âmbito não estivessem sendo engendradas (como no caso do Projeto Arte e Saúde, responsável pela formação dos artistas e por eventos culturais da rede de saúde mental do município, que comentaremos adiante) ou que essa discussão não estivesse em pauta. De acordo com entrevista feita com um dos coordenadores de Saúde Mental do município em 2008, havia um debate sendo estabelecido nesta instância em relação aos Centros de Convivência e Cultura, no intuito de definir se a melhor forma de incentivar as ações culturais seria mesmo a construção de um Centro voltado especificamente para os usuários da rede de Saúde Mental.

Apesar de conhecer e citar algumas experiências, como a de Belo Horizonte e de Campinas, nosso interlocutor falou que ainda não havia uma posição definida a esse respeito por parte da gestão. Ele questionou se seria realmente preciso ter um lugar demarcado para se conviver, ter acesso à cultura e ao lazer e para, de fato, haver um processo de inclusão.
No entanto, fora frisado várias vezes durante nossa conversa que a gestão tinha a preocupação em não reduzir a Reforma Psiquiátrica na cidade à criação de CAPS, investindo, para tanto, na diversificação dos equipamentos da rede e nas ações em parcerias com outros estabelecimentos (como as Universidades), movimentos comunitários, ONGs e projetos.

Vemos, assim, que a questão sobre a implantação dos Centros de Convivência e Cultura em nível nacional atualiza-se no município em que trabalhamos, com suas especificidades locais. Contudo, observamos que tal debate é perpassado por questionamentos mais gerais, como em relação às políticas intersecretariais/ intersetoriais necessárias à ampliação dos limites da Reforma, inclusive no que tange ao financiamento de equipamentos como os Centros de Convivência e Cultura que não são espaços, por definição, sanitários.

Tais políticas devem ser firmadas e engendrar ações, serviços e projetos que possibilitem a transposição das fronteiras da rede estritamente sanitária, sustentando a desmanicomialização concreta através dos recursos comunitários de suporte social, em cogestão com as secretarias de cultura, ação social, habitação e assim por diante (Dimenstein \& Liberato, 2009). Isso, porém, ainda não está bem estabelecido, segundo nossa observação, e nos faz pensar acerca da noção de intersetorialidade como ponto nodal da construção de redes assistenciais e de suporte. $\mathrm{O}$ princípio da intersetorialidade constitui-se como base fundamental para o paradigma da atenção psicossocial, pois possibilita a superação da fragmentação tanto da atenção e do cuidado, como também das políticas, ações e conhecimentos no campo da saúde mental, partindo das situações cotidianas e das necessidades dos usuários.

Em relação à discussão sobre ter ou não um Centro de Convivência e Cultura voltado às necessidades dos usuários da rede saúde mental, apesar de concordarmos com nosso entrevistado quanto à necessidade de não se delimitar os espaços possíveis de circulação desses, incentivando sua participação e seu trânsito em tudo que a cidade oferece, questionamos se não seria importante, devido à história de exclusão e institucionalização dessas pessoas, existirem locais que possam servir mesmo como trampolim para outras vivências e relações possíveis dentro da comunidade na qual estão inseridos. Não defendemos que sejam os únicos lugares, mas que se configurem como opções de acolhimento, de experiência, de trocas.

Um dos consultores do Projeto Arte e Saúde, entrevistado em 2009, enfatizou essa perspectiva ao dizer que, apesar de possuir alguns outros equipamentos sociais de convivência, esses não estão 
preparados para trabalhar com o universo da luta antimanicomial, visto que ainda há uma carência de formação dos profissionais que atuam na área cultural (animadores, produtores, gestores). Não adiantaria, então, criar novos equipamentos se não há pessoas com qualificação apropriada para esse trabalho. Ao refletir sobre a criação de novos espaços de convivência e cultura em interface com a saúde mental, surge a necessidade de pensarmos a partir do conceito de rede, que diz respeito não somente a justaposição material de equipamentos e serviços, mas a uma lógica de operação conectiva. Assim, mais do que apenas construir novos lugares, é essencial a produção de um funcionamento que articule ações, intenções e afetos.

Torna-se claro, pois, que são necessárias ações macropolíticas, de âmbito governamental, que deem suporte à criação e efetivação de espaços, inclusive no que tange ao financiamento dessas práticas, que possibilitem uma maneira diferente de ocupar a cidade por aqueles que sempre sofreram distintas formas de exclusão. Todavia, é urgente também ir além. As lutas por novos modos de sociabilidade devem ocorrer coextensivamente nos níveis micro e macro, lembrando que até a institucionalização e formalização de alguma prática no âmbito da política estatal muitos fluxos e linhas estão em movimento, produzindo diferentes agenciamentos e forças instituintes que transbordam aquilo que está posto, possibilitando invenções e acontecimentos.

Não basta, portanto, encaixar nos espaços da cidade aquilo que pulsa como diferença ou, dizendo melhor, adaptar as relações e modos de subjetivação às possibilidades que nos aparecem como dadas e acabadas. É fundamental produzirmos outras relações, outras cidades e espaços possíveis, outras temporalidades que falem desse processo de movimento e criação. Falamos, pois, de ruídos, interferências, desmanches e composições. Dentro dessa perspectiva, pensamos que as ideias e os afetos produzidos a partir das ações coletivas preconizadas pelo Projeto Arte e Saúde podem nos apontar focos de resistência para uma nova forma de ocupar, habitar e produzir relações de sociabilidade, bem como explicitar alguns estrangulamentos que impedem tais forças de compor arranjos subjetivos potentes e inovadores na interseção cultura/saúde mental.

O Projeto Arte e Saúde, conforme já adiantamos, surgiu da necessidade de trabalhar esta interface cultura/arte e saúde mental junto à embrionária rede municipal de serviços substitutivos que estava sendo montada no ano de 2006. O projeto, primeiramente pensado sob a forma de uma consultoria em parceria com um instituto de âmbito privado, foi concebido a partir de dois grandes eixos: inserção de artistas nas equipes dos CAPS, incluindo sua capacitação e também de outros profissionais dos serviços interessados na articulação arte-cuidado; e o fomento à ação cultural nesse contexto. Atualmente, consolidouse como parte efetiva da Coordenação do Colegiado de Saúde Mental.

Ao longo de nossa aproximação com as ações do projeto, pudemos perceber que este primeiro eixo sempre foi bastante valorizado, inclusive por sua proposta inovadora (levar os artistas para dentro dos CAPS a partir de uma formação específica para este trabalho) dentro do contexto da época. No tocante ao segundo eixo, referente às ações culturais, tomamos conhecimento de alguns eventos comemorativos, como o Dia da Luta Antimanicomial (18 de maio) e o Dia Mundial da Saúde Mental (10 de outubro), assim como de atividades mais sistemáticas como o "Tô de Lua" e a produção do bloco carnavalesco "Doido é tu!". O primeiro diz respeito a um sarau/confraternização, realizado a cada mês em um lugar diferente, envolvendo usuários dos serviços, familiares, profissionais e a comunidade daquele entorno a partir da música e de outros tipos de arte ${ }^{4}$. Já o bloco tem como proposta gerar um pensamento crítico na sociedade em relação à loucura e promover alternativas de inclusão.

Observamos que o Projeto Arte e Saúde possui muitas potencialidades de ação e reflexão, porém também enfrenta muitos engessamentos e obstáculos, haja vista a rede de assistência em saúde mental ainda estar em processo de consolidação e não existir efetivamente redes intersetoriais que envolvam saúde e cultura no município. Além disso, notamos também que o primeiro eixo (voltado para a formação e a prática artística dentro dos CAPS) havia ganhado mais atenção (no sentido de uma maior organização e investimento mais sistemático) do que o segundo. Tal constatação nos fez avaliar que, se por um lado, este era um avanço fundamental, pois mais pessoas estavam se tornando capacitadas para refletir acerca da potência da arte como tecnologia psicossocial e propor novas estratégias de atenção e cuidado, que poderiam, inclusive, extrapolar os limites físicos e burocráticos do serviço; por outro, poderia também ocorrer uma cronificação dessas ações apenas no âmbito assistencial. Embora a primeira hipótese nos parecesse mais positiva e fosse também a aposta dos consultores do Projeto, percebemos algumas dificuldades nesse processo.

Notamos que este movimento entre dentro e fora dos serviços nem sempre ocorria conforme o planejado. Em certos casos, tanto artistas como profissionais que passaram pela formação estavam 
trabalhando com uma perspectiva ainda restrita do uso da arte, apenas como instrumento terapêutico stricto sensu dentro dos grupos nos CAPS. Ocorria, ainda, que muitos desses artistas foram contratados em regime de $20 \mathrm{~h}$ de trabalho semanal apenas e ainda tinham que dividir seu tempo entre dois (ou até três) CAPS distintos. Com o aumento da demanda dos usuários por grupos com artistas, essa situação ficou ainda mais complicada, produzindo uma cristalização dessas atividades nos serviços.

Obviamente, não estamos defendendo que as possibilidades de uso da arte nas atividades de cunho terapêutico e seu aumento no cotidiano da assistência à saúde mental sejam um problema. Ao contrário. Tivemos a oportunidade de ouvir alguns relatos tanto de profissionais quanto de usuários sobre o alcance e a efetividade desses trabalhos no processo de cuidado. O ponto nevrálgico deste debate é que se faz necessário articular novos possíveis para o campo da Reforma Psiquiátrica, que se estendam além do cuidado estruturado como assistência. É preciso produzir saídas dos serviços especializados para evitar novas institucionalizações. É urgente potencializar circulações, encontros, inserções/interseções, contatos diversos, que deem um novo impulso a todos os envolvidos e ao próprio movimento da Reforma, que, como defendemos, diz respeito a uma mudança na forma de estar e conviver com a diferença, à criação de novos mundos.

Nesse sentido, observamos ainda que alguns artistas e profissionais de outras áreas da saúde mental, em parceria com a equipe do Projeto Arte e Saúde, conseguiram pôr em movimento ações culturais, como as já citadas, que envolviam de modo mais efetivo a comunidade, disseminando ideias e práticas antimanicomiais e desinstitucionalizantes. Contudo, a dificuldade de mobilização dos diferentes atores sociais, assim como a sedução do ideal terapêutico clínico ainda hegemônico como forma privilegiada de cuidado e atenção e, principalmente, a carência de diferentes parcerias (seja no âmbito público ou não) inibe sobremaneira a produção de ações mais sistematizadas e permanentes.

Essas observações nos levam a algumas interrogações imprescindíveis, que nos colocam novamente a necessidade (e também a dificuldade) de pensar e habitar os espaços entre a macro e a micropolítica. Vejamos: se, por um lado, entendemos que a cristalização de certas práticas e atividades faz parte de um processo de institucionalização, que é próprio da dinâmica dos arranjos sociais e subjetivos, como continuar a pôr em movimento fluxos instituintes, linhas de fuga? De que modo manejar esses dois planos, tão distintos e, ao mesmo tempo, contíguos? Parece-nos que esse é o principal desafio em relação às ações e pensamentos que constituem a Reforma e a produção de um novo paradigma de atenção.

Intentando perseverar neste exercício de deslocamento entre os planos de organização (formado pelo que se encontra instituído socialmente no plano da macropolítica e que homogeneiza a vida) e de consistência (constituído por forças moleculares que animam encontros e invenções de sentido no plano micropolítico), como nos ensina Romagnoli (2010), inspirada por Deleuze e Guattari (1996), é preciso que nos perguntemos: será, então, que as ações culturais promovidas pelo Projeto Arte e Saúde podem produzir fissuras na mesmidade do uso corrente da arte? Para tanto, elas precisariam de mais sistematização, constância ou homogeneidade (no sentido de que as pessoas se engajassem do mesmo modo)? Mas, se não for assim, será possível construir uma nova política baseada na atenção psicossocial?

A pergunta que nos parece caber, portanto, refere-se a quais processos de atualização queremos fomentar e como fazê-lo, sabendo-os provisórios e indeterminados. Retomamos, assim, nossa discussão para pensar a respeito das possibilidades da arte como uma tecnologia psicossocial, posta para funcionar pelo Projeto Arte e Saúde, que contribua para a desestabilização das formas e das funções já postas, a partir da intensidade dos acontecimentos. Nesse sentido, desejamos nos focar na experiência do bloco Doido é tu!, que nos surgiu como um analisador fundamental dessa questão.

Acompanhar de modo mais próximo a concepção e estruturação do bloco para o carnaval de 2010 não se mostrou importante, apenas, para identificarmos e ponderarmos a respeito das dificuldades organizacionais ou confirmarmos a hipótese de que "a alegria é a prova dos nove" e defendermos a arte como ferramenta de intervenção potente na construção de um novo lugar e de uma outra visibilidade para a questão da loucura. Aproximarmo-nos, de modo intensivo, de tal experiência nos propiciou ser afetados efetivamente pela produção de outros vínculos, de alegrias e dúvidas, de nos deslocarmos e reconstruirmos outras formas de pesquisar, estar, intervir, militar.

No ano do carnaval em questão, duas conquistas importantes foram alcançadas pelos organizadores. A primeira referiu-se à possibilidade de, pela primeira vez, o bloco poder sair na avenida concorrendo como bloco oficial. A segunda, a de ter ganhado um edital municipal (voltado para agremiações carnavalescas), que proporcionou a saída do bloco durante o período de pré-carnaval da cidade. Ambas as novidades foram 
motivo de muita comemoração e felicidade, mas também de muitos afazeres por parte da equipe.

Participamos de algumas reuniões de preparação da saída do bloco no pré-carnaval e também de sua saída oficial no carnaval e vimos, novamente, que o trabalho findava sob a responsabilidade efetiva de apenas algumas pessoas. No começo, observamos, ainda, que, embora os usuários tivessem sido convidados a participar desse momento de planejamento e organização, praticamente apenas os técnicos (principalmente os artistas e terapeutas ocupacionais) estavam comparecendo às reuniões. No decorrer do processo, contudo, pudemos observar uma maior adesão dos usuários, inclusive acompanhando o relato de alguns deles acerca da importância de poder participar de atividades e oficinas fora do espaço do serviço ${ }^{5}$.

Consideramos que tal ausência é perpassada por múltiplos fatores, dentre eles a dificuldade objetiva de alguns usuários em transitar pela cidade, passando também pelo fato de, muitas vezes, não se sentirem aptos a colaborar ou mesmo estarem cristalizados apenas no papel de receptores das atividades. Esse tema foi debatido em uma reunião na qual se definiu algumas estratégias para a motivação e participação daqueles usuários que se interessassem. Organizaramse, então, algumas oficinas, relativas à confecção de adereços e de instrumentos musicais, numa Fundação parceira do Colegiado de Saúde Mental, onde ocorriam as reuniões do bloco, abertas a quem se interessasse (usuários e técnicos). As pessoas que participassem de tais oficinas ficariam, depois, responsáveis em compartilhar o conhecimento aprendido em seus próprios CAPS. Além disso, um usuário do CAPS, artista plástico, também ficou responsável por ministrar uma oficina de adereços, mas havia solicitado que essa acontecesse no serviço que ele frequentava.

Pudemos perceber que todo esse processo de organização do bloco, embora bastante cansativo, foi muito proveitoso para a consolidação do mesmo, no sentido de viabilizar um tempo para que as pessoas que se interessavam pudessem ir se aproximando e se apropriando singularmente dessa experiência. Constatamos isso de modo mais claro ao longo dos três sábados de pré-carnaval em que estivemos presentes (ao todo, foram quatro sábados antes do carnaval). Exemplos como a apropriação da banda do CAPS de sua função, bem como o relato dos participantes em relação àquela experiência (como no caso da única integrante da referida banda que era uma senhora e que teve que lidar com o receio da família e dela mesma em relação àquela atividade, descobrindo, por fim, gostar muito de música e de carnaval) nos fizeram perceber o bloco como um dispositivo potencializador de transformações nas relações de cada um consigo próprio e com os outros.

Em nossos registros, escritos após cada dia num "diário de sensações", como denominamos, fomos buscando acompanhar a dinâmica daqueles encontros e a produção de algo que ia além de um simples bloco de carnaval: novas possibilidades de existência. No primeiro sábado, as principais impressões que tivemos foram uma mistura de estranhamento e timidez. Foram poucas pessoas da rede (profissionais e gestores), a estrutura ainda estava sendo organizada, a comunidade do entorno da pracinha na qual o bloco se reunia aparentava um misto de indiferença, desconfiança e curiosidade (esta última caraterística identificada, principalmente, com as crianças) com toda aquela movimentação, ao mesmo tempo em que os poucos usuários presentes também ainda pareciam um pouco deslocados.

Ao longo do tempo, todos foram ficando mais soltos, aproveitando mais, porém voltamos para casa com muitas inquietações: Será que as pessoas iriam participar (principalmente os usuários e familiares)? Como enfrentar a dificuldade de locomoção das pessoas de outros bairros? Será que o bloco deveria ser itinerante? Isso seria viável? E de que maneira poderíamos aproximar mais o bloco da comunidade? Seria necessário fazê-los entender a proposta daquela ação? Questionamo-nos a nós mesmos também. Quanto de preconceito em relação àquele lugar desconhecido também carregávamos?

Analisando as questões levantadas, vemos agora que muitas delas foram respondidas pelo próprio andar da experiência. De fato, pessoas que moravam mais longe enfrentaram mais dificuldades em poder estar lá, e a presença maior sempre foi de usuários daquele território. Conversando com nosso interlocutor do Projeto Arte e Saúde, que era também o principal organizador do bloco, seria necessário pensar em alternativas para esse problema, mas a possibilidade de o bloco ser itinerante, embora interessante, não seria viável em termos de organização. Em relação à participação, observamos que ela foi aumentando ao longo das semanas e que culminou na apresentação do bloco no carnaval, com um número bem significativo de participantes (entre usuários, familiares, técnicos e gestores).

No que tange à aproximação com a comunidade, notamos também que esse processo todo foi fortalecendo o vínculo das pessoas que ali habitavam com o bloco e com a própria Fundação, que tem sede em frente ao local onde acontecia a concentração. Ademais, houve oportunidades de nos juntamos a 
outros blocos de pré-carnaval que passavam no bairro e sairmos juntos desfilando, o que também proporcionou novas possibilidades de integração.

Constatamos, então, o que já sabíamos, mas tínhamos esquecido: a questão de excluir ou incluir, ser poroso à alteridade ou não, conviver com a diferença ou querer adequá-la, não passa somente por uma questão de compreensão racional, de entendimento consciente. Deleuze (2003) já nos advertia que a inteligência intervinha sempre depois, primeiramente seria preciso sentir o afeto violento de um signo.

Assim, apreendemos também que essa mudança diz respeito, sobretudo, à produção de afecções, de encontros que aumentam a potência de vida, encontros alegres, produtores de "zonas de comunidade", como nos expõe Teixeira (2004), inspirado pelo pensamento espinosano. Zonas de comunidade que podem nos levar a uma relação distinta com o outro, uma relação a partir de suas singularidades.

Por fim, observamos que o processo de invenção de novos modos de subjetivação e sociabilidade convive com a manutenção de formas cristalizadas de relação. Percebemos isso, por exemplo, na maneira de alguns profissionais que lá se fizeram presentes. Alguns pareciam pouco à vontade em se misturarem efetivamente com os usuários; outros passavam a impressão de que estavam ali para cumprir uma obrigação profissional ou apenas manter um discurso antimanicomial, embora revelassem, por outras vias, também os seus mandatos sociais e sua dificuldade de passar do discurso à prática.

Parece-nos importante destacar essa percepção não no sentido de apontar falhas e equívocos. $\mathrm{O}$ que gostaríamos de indicar é a necessidade de um constante movimento de análise e reflexão individual e coletiva, em que seja possível rever certas posturas e dificuldades, buscando possibilidades, dentro dos limites de cada um, de colaborar com a construção desse processo de transformação social. Acrescentamos, inclusive, que o fato de alguém (profissional, gestor, usuário...) não se interessar em participar da atividade $\mathrm{x}$ ou y não significa, absolutamente, falta de comprometimento; pode, simplesmente, significar pouca afinidade com tal evento. Mas nos parece fundamental atentar para o fato de que, ali estando, é interessante produzir bons encontros e se deixar afetar por eles.

Como dissemos antes, todo esse processo de organização e participação durante o pré-carnaval fortaleceu ainda mais a experiência da saída do bloco no desfile oficial do carnaval. Além de uma bela apresentação (com apenas alguns problemas no áudio do carro de som), todos que participaram puderam experimentar uma alegria transbordante, um riso compartilhado, que abole, pelo menos por um átimo, as diferenças hierárquicas e sociais (Lampoglia, Miotello, \& Romão, 2011), mas não as singularidades.

O desfile animou não só a plateia, mas todo o entorno da avenida, pois não paramos ao chegar ao local da dispersão dos blocos. Envolvidos por essa alegria imanente, continuou-se o desfile pelas ruas próximas, sem carro de som, sem a organização exigida oficialmente, mas espalhando força de mudança e invenção por onde se passava. A cidade ganhou novas cores, novos sorrisos, outros caminhos. E o encontro entre SM, arte, cultura e carnaval apontou outras possibilidades, ainda que parciais e temporárias, para nossa realidade.

\section{Conclusão}

No decorrer deste artigo, intentamos abrir um campo de discussão no tocante à relação entre arte, loucura e a cidade. Entendemos que, embora essa temática seja sempre revisitada e debatida nos trabalhos sobre a Reforma Psiquiátrica, é importante atentarmos para as diferentes possibilidades que tal encontro pode proporcionar. Pensar essas três esferas em constante movimento e em reconstrução permanente de suas ligações faz-nos inquirir cada contexto em sua especificidade, com suas potencialidades e riscos.

No caso do nosso olhar, percebemos que a despeito das dificuldades para a articulação de ações intersetoriais mais efetivas no plano macropolítico, estão sendo produzidos acontecimentos micropolíticos que põem em movimento outras formas de convivência com a diferença, com o território e com a experiência estética e sensível, plasmando outras perspectivas de subjetivação, saúde e sociabilidade que transbordam para além da assistência sanitária estrita e apontam outros caminhos a serem trilhados no processo de desinstitucionalização e da criação de um novo paradigma de cuidado e atenção.

\section{Notas}

Utilizamo-nos aqui da noção de acontecimento trabalhada no pensamento deleuziano, na qual, para além da sua efetuação concreta (atualização de determinado estado de coisas), existe também uma dimensão pré-individual (intensiva), constituída por uma multiplicidade de forças virtuais. Essa dimensão intensiva do acontecimento assinala, portanto, o encontro com uma exterioridade prenhe de devires, produtores de novos sentidos e formas.

2 O processo de investigação, pesquisa e intervenção artística denominado Interferência: San Pedro foi um projeto desenvolvido pelo Núcleo de Dança do Alpendre, tendo 
como proposta o diálogo de diferentes linguagens artísticas (dança, vídeo e poesia) e, como resultado final, a produção de um vídeo-dança, um documentário e uma publicação.

3 É necessário sublinhar que a distinção entre a macro e a micropolíticanãoresidenotamanho, extensão ou abrangência de tais planos, como os termos podem sugerir. De acordo com Deleuze e Guattari (1996), o que as distingue são seus modos de funcionamento. Enquanto a macropolítica opera a partir da sobrecodificação e estratificação das intensidades, a micropolítica atua na sustentação do intensivo, daquilo que escapa à segmentarização.

4 Durante a pesquisa, todavia, constatamos que este evento não estava acontecendo com uma periodicidade regular, o que já nos indica algumas dificuldades relativas à operacionalização de ações culturais mais permanentes no contexto da saúde mental.

5 Sobre esta questão das fronteiras entre dentro-fora dos serviços de assistência, parece-nos fundamental retomar a ideia de que tais dimensões vão além da questão espacial estrita. Como discutido ao longo do trabalho, pensar e trabalhar com a perspectiva da exterioridade diz, sobretudo, de uma lógica de funcionamento diversa, que possibilita novas associações e enfrentamentos.

\section{Agradecimento}

À CAPES, pela bolsa de estudos concedida a primeira autora durante o curso de Doutorado que originou este trabalho.

\section{Referências}

Deleuze, G. (2003). Proust e os signos. Rio de Janeiro: Forense Universitária.

Deleuze, G. \& Guattari, F. (1992). O que é a filosofia? São Paulo: Ed. 34

Deleuze, G. \& Guattari, F. (1996). Mil Platôs - Capitalismo e Esquizofrenia (Vol. 3). São Paulo: Ed. 34.

Dimenstein, M. \& Liberato, M. T. C. (2009, janeiro/abril). Desinstitucionalizar é ultrapassar fronteiras sanitárias: o desafio da intersetorialidade e do trabalho em rede. Cadernos Brasileiros de Saúde Mental, 1(1), 212-222.

Feitosa, C. (2004). Explicando a filosofia com arte. Rio de Janeiro: Ediouro.

Foucault, M. (2003). Microfisica do poder (18 ed.). Rio de Janeiro: Graal.

Lampoglia, F., Miotello, V., \& Romão, L. M. S. (2011, janeiro/ abril). Do desfile na avenida ao camarote: um olhar discursivo sobre o carnaval nos cartuns de Angeli. Linguagem em (Dis) curso, 11(1), 81-102.

Lancetti, A. \& Amarante, P. (2009). Saúde Mental e Saúde Coletiva. In G. W. S. Campos, M. C. S. Minayo, M. Akerman, M. Drumond Júnior, \& Y. M. Carvalho (Orgs.), Tratado de Saúde Coletiva (2a ed., pp. 615-634). São Paulo: Hucitec; Rio de Janeiro: Ed. Fiocruz.
Martins, B. A. (2009). Ode à Crueldade, ou a arte para pensar a desinstitucionalização. Dissertação de Mestrado, Universidade Federal Fluminense, Niterói - Rio de Janeiro.

Ministério da Saúde. Secretaria de Atenção à Saúde. DAPE. Coordenação Geral de Saúde Mental. (2005). Reforma psiquiátrica e política de saúde mental no Brasil. Documento apresentado à Conferência Regional de Reforma dos Serviços de Saúde Mental: 15 anos depois de Caracas. OPAS. Brasília: Ministério da Saúde.

Oliveira, E. J. (2004). San Pedro. Fortaleza: Autor.

Oneto, P. D. (2006). Vontade de arte e resistência ao presente. In V. R. F. Colaço, F. P. H. A. Pinheiro, \& J. F. Silva (Orgs.), Reflexos III - PET-Psicologia/UFC: Políticas de Subjetivação nas Práticas Sociais (pp.45-55). Fortaleza: Universidade Federal do Ceará, Edições UFC, Programa de Educação Tutorial.

Pelbart, P. P. (1993). A Nau do Tempo Rei: sete ensaios sobre o tempo da loucura. Rio de Janeiro: Imago.

Rancière, J. (2005). Política da arte. Acesso em 04 de setembro, 2007, em http://www.sescsp.org.br/sesc/images/upload/ conferencias/206.rtf

Romagnoli, R. C. (2010). Entre a educação e a saúde: o desafio das redes. Pesquisas e Práticas Psicossociais, 4(2), 182-192.

Santos, M. (2005). O retorno do território. Acesso em 22 de dezembro, 2009, em http://bibliotecavirtual.clacso.org.ar/ar/ libros/osal/osal16/D16Santos.pdf

Teixeira, R. R. (2004). As redes de trabalho afetivo e a contribuição da saúde para a emergência de uma outra concepção de público. Acesso em 03 de março, 2007, em http://www.corposem.org/rizoma/index.html

Recebido em: 22/03/2012

Revisão em: 06/05/2012

Aceite em: 27/07/2012

Mariana Tavares Cavalcanti Liberato é Psicóloga. Mestre e Doutora em Psicologia pela Universidade Federal do Rio Grande do Norte (UFRN). Professora do curso de Psicologia da Faculdade Nordeste/ FANOR. Endereço: Av. Santos Dumont, 7800. Dunas. Fortaleza/CE, Brasil. CEP 60191-156. Email: mariana_liberato@yahoo.com.br

Magda Dimenstein é Doutora em Saúde Mental pela Universidade Federal do Rio de Janeiro (UFRJ). Professora Titular do Programa de Pós-Graduação em Psicologia da Universidade Federal do Rio Grande do Norte (UFRN). Email: magda@ufrnet.br

\section{Como citar:}

Liberato, M. T. C. \& Dimenstein, M. (2013). Arte, loucura e cidade: a invenção de novos possíveis. Psicologia \& Sociedade, 25(2), 272-281. 